\title{
Quantum chemical assessment of benzimidazole derivatives as corrosion inhibitors
}

\author{
Hasan R Obayes ${ }^{1}$, Ghadah H Alwan², Abdul Hameed MJ Alobaidy ${ }^{3}$, Ahmed A Al-Amiery, ${ }^{3,4^{*}}$, Abdul Amir H Kadhum ${ }^{4}$ \\ and Abu Bakar Mohamad ${ }^{4}$
}

\begin{abstract}
Background: The majority of well-known inhibitors are organic compounds containing multiple bonds and heteroatoms, such as $\mathrm{O}, \mathrm{N}$ or $\mathrm{S}$, which allow adsorption onto the metal surface. These compounds can adsorb onto the metal surface and block active surface sites, reducing the rate of corrosion.

Results: A comparative theoretical study of three benzimidazole isomers, benzimidazole (Bl), 2-methylbenzimidazole $\left(2-\mathrm{CH}_{3}-\mathrm{BI}\right)$, and 2-mercaptobenzimidazole (2-SH-BI), as corrosion inhibitors was performed using density functional theory (DFT) with the B3LYP functional basis set.

Conclusions: Nitro and amino groups were selected for investigation as substituents of the three corrosion inhibitors. Nitration of the corrosion inhibitor molecules led to a decrease in inhibition efficiency, while reduction of the nitro group led to an increase in inhibition efficiency. These aminobenzimidazole isomers represent a significant improvement in the inhibition efficiency of corrosion inhibitor molecules.
\end{abstract}

Keywords: Benzimidazole, B3LYP, Corrosion, DFT, Inhibitor

\section{Introduction}

Corrosion is an electrochemical process by which metallic structures are destroyed gradually through anodic dissolution [1]. Protection of metallic surfaces can be achieved by the addition of specific compounds known as corrosion inhibitors [2]. Among the numerous corrosion prevention measures available, corrosion inhibitors, which have the advantages of economy, high-efficiency, and facile and feasible use, have been widely applied in various fields. As the importance of environmental protection has become increasingly recognized, the development of new green corrosion inhibitors has received increasing attention [3-5]. A variety of organic compounds containing heteroatoms $(\mathrm{N}, \mathrm{O}, \mathrm{S})$ that can donate electron pairs have been used to inhibit brass corrosion in various aggressive electrolytes [6-11]. The use of organic inhibitors for preventing corrosion is a promising alternative. These inhibitors are usually adsorbed on the metal

\footnotetext{
* Correspondence: dr.ahmed1975@gmail.com

${ }^{3}$ Environmental Research Center, University of Technology (UOT), Baghdad 10001, Iraq

${ }^{4}$ Department of Chemical \& Process Engineering, Universiti Kebangsaan Malaysia (UKM), Bangi, Selangor 43000, Malaysia

Full list of author information is available at the end of the article
}

surface by the formation of a coordinate covalent bond (chemical adsorption) or an electrostatic interaction between the metal and inhibitor (physical adsorption) [12]. This adsorption produces a uniform film on the metal surface, which reduces or prevents contact with the corrosive medium [13]. Because organic inhibitors act by adsorption on the metal surface, the efficiency of these compounds depends strongly on their ability to form complexes with the metal [14]. Both $p$ electrons and polar groups containing sulfur, oxygen and nitrogen are fundamental characteristics of this type of inhibitor. The polar functional groups serve as the chelation center for chemical adsorption [15]. Considerable effort has been devoted to studying the metallic corrosion inhibition properties of benzimidazole and its derivatives [16-20]. Benzimidazole is a heterocyclic aromatic organic compound with a bicyclic structure comprising fused benzene and imidazole rings [21]. The hydrogen atoms on the rings can be substituted by other groups or atoms. Some derivatives of benzimidazole are excellent corrosion inhibitors for metals and alloys in acidic solution; the level of inhibition varies with substituent groups and substituent positions on the imidazole ring [22-26]. The effects of the molecular structure on chemical reactivity have been studied extensively 


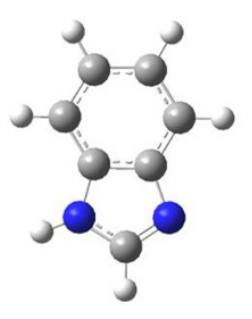

Benzimidazole (BI)

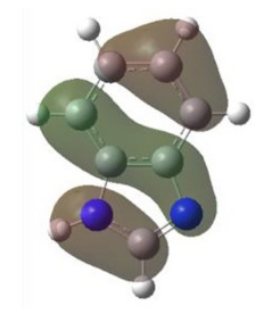

HOMO

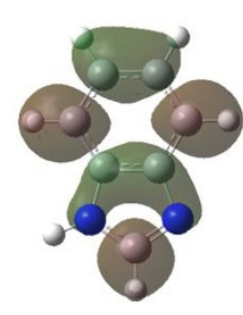

LUMO

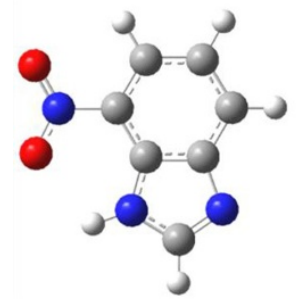

4-NO$-\mathrm{BI}$

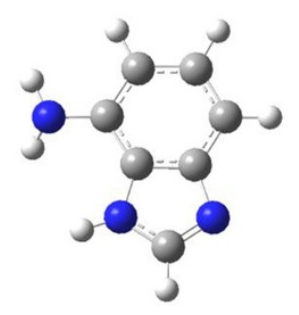

4-NH$-\mathrm{BI}$

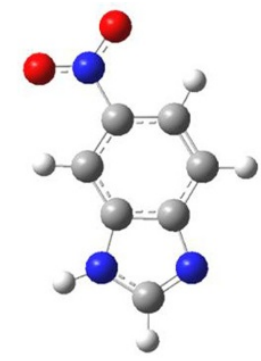

$5-\mathrm{NO}_{2}-\mathrm{BI}$

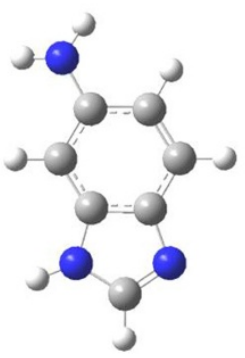

5-NH $-\mathrm{BI}$

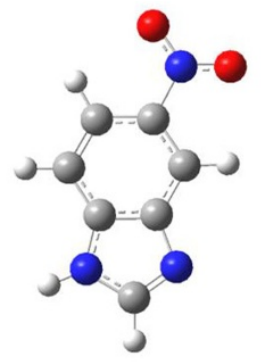

6-NO2-BI

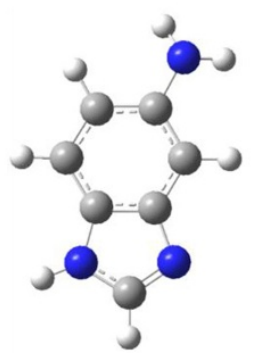

6-NH$-\mathrm{BI}$

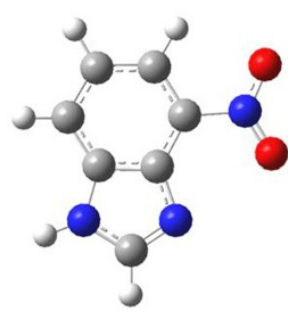

7-NO2-BI

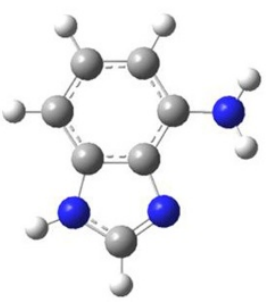

7-NH -BI

Figure $1 \mathrm{~B} 3 \mathrm{LYP} / 6-31 \mathrm{G}++(\mathrm{d}, \mathrm{p})$ optimized geometries, HOMO and LUMO of benzimidazole (BI) and the optimized geometries of the eight models.

[27-31]. Density functional theory (DFT) was recently successfully applied to describe the structural importance of corrosion inhibitors and their adsorption efficiency on metal surfaces [32,33]. As part of the development of novel, more efficient organic corrosion inhibitors, several quantum-chemistry studies have been performed that relate inhibition efficiency to the molecular properties of the different types of compounds. The molecular structure and the electronic parameters, which can be obtained from theoretical calculations and include the HOMO

Table 1 Quantum-chemical parameters for benzimidazole (BI) and eight models as determined by DFT at the B3LYP/6-31G++ (d,p) level

\begin{tabular}{lrrrccc}
\hline Molecules & Total Energy a.u. & EHOMO eV & ELUMO eV & Gap energy (ELUMO - EHOMO) eV & lonization potential (I) & Electron affinity (A) \\
\hline BI & -379.9673 & -6.4567 & -0.8778 & 5.5789 & 6.4567 & 0.8778 \\
4-NO2-Bl & -584.5358 & -7.3076 & -3.1016 & 4.2060 & 7.3076 & 3.1016 \\
4-NH2-Bl & -435.3409 & -5.7838 & -0.7295 & 5.0543 & 5.7838 & 7.2878 \\
5-NO2-Bl & -584.5321 & -7.2878 & -2.8316 & 4.4562 & 5.5060 & 2.7295 \\
5-NH2-Bl & -435.3418 & -5.5060 & -0.6514 & 4.8546 & 7.2546 & 0.6514 \\
6-NO2-Bl & -584.5319 & -7.2546 & -2.6667 & 4.5879 & 5.4986 & 2.6667 \\
6-NH2-Bl & -435.3409 & -5.4986 & -0.7600 & 4.7386 & 7.2404 & 0.7600 \\
7-NO2-Bl & -584.5220 & -7.2404 & -2.7045 & 4.5359 & 5.4235 & 2.7045 \\
7-NH2-Bl & -435.3472 & -5.4235 & -0.4863 & 4.9372 & & 0.4863 \\
\hline
\end{tabular}


Table 2 The calculated inhibition efficiency \% of benzimidazole (BI) and eight models

\begin{tabular}{lccll}
\hline Molecules & $\boldsymbol{I}_{\text {add. }} \%$ & $\boldsymbol{l e}_{\text {add. }} \%$ & \multicolumn{2}{l}{ Inhibition efficiency \% } \\
\cline { 3 - 5 } & & & Theoretical $\left(\boldsymbol{e}_{\text {theor. }}\right)$ & Experimental \\
\hline $\mathrm{BI}$ & 0 & 0 & 73.800 & 73.8 \\
4-NO2-BI & -13.178 & -9.725 & 64.075 & - \\
4-NH2-BI & +10.422 & +7.691 & 81.491 & - \\
5-NO2-BI & -12.872 & -9.500 & 64.300 & - \\
5-NH2-BI & +14.724 & +10.866 & 84.666 & - \\
6-NO2-BI & -12.358 & -9.120 & 64.680 & - \\
6-NH2-BI & +14.839 & +10.951 & 84.751 & - \\
7-NO2-BI & -12.138 & -8.958 & 64.842 & - \\
7-NH2-BI & +16.002 & +11.809 & 85.609 & - \\
\hline
\end{tabular}

(highest occupied molecular orbital) energy, the LUMO (lowest unoccupied molecular orbital) energy, and the energy of the gap, influence the inhibitor activity as well as reactivity, which can be treated by HSAB theory [34-42]. The aim of this work is to elucidate the electron configuration of benzimidazole (BI), 2-methylbenzimidazole (2-CH3-BI) and 2-mercaptobenzimidazole (2-SH-BI) inhibitors using DFT and determine the relationship between molecular structure and inhibition efficiency. The established correlation will facilitate the design and synthesis of new inhibitors with improved inhibition efficiency.

\section{The calculation method}

To calculate the ground-state geometries, Gaussian 03, Revision C.01 [43] was optimized to a local minimum

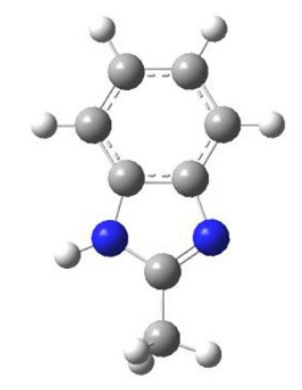

2-methylbenzimidazole

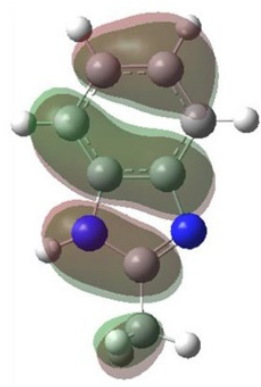

номо

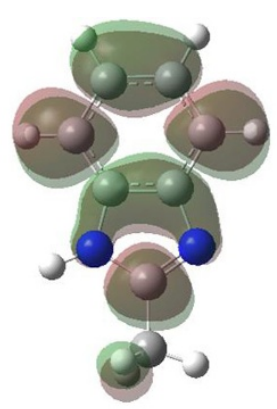

LUMO
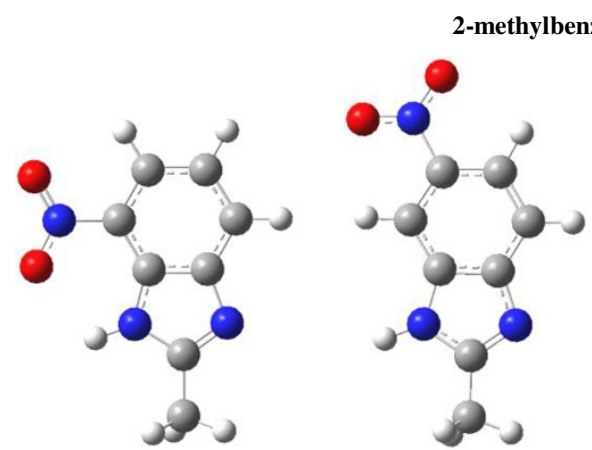

midazole

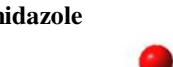

2-methylbenzimidazole
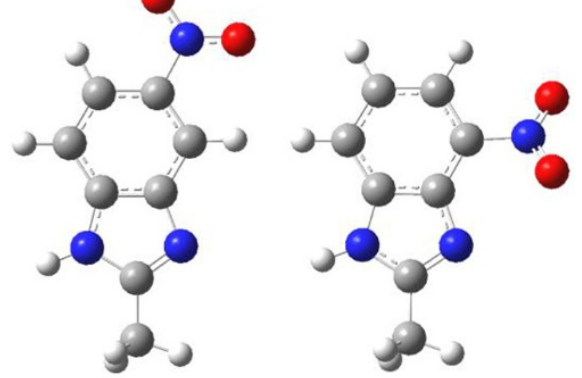

4-NO2-2- $\mathrm{CH}_{3}-\mathrm{BI}$

$5-\mathrm{NO}_{2}-2-\mathrm{CH}_{3}-\mathrm{BI}$

6-NO2-2- $\mathrm{CH}_{3}-\mathrm{BI}$

7-NO2-2- $\mathrm{CH}_{3}-\mathrm{BI}$

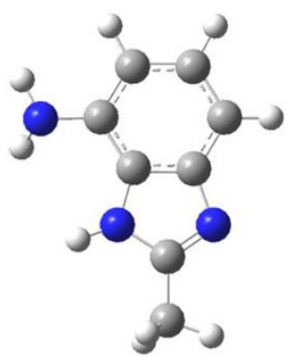

4-NH $2-2-\mathrm{CH}_{3}-\mathrm{BI}$

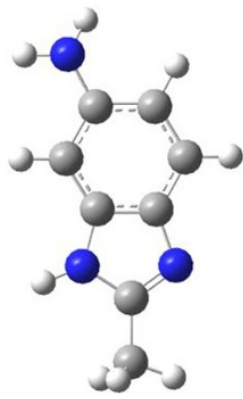

5-NH $2-2-\mathrm{CH}_{3}-\mathrm{BI}$

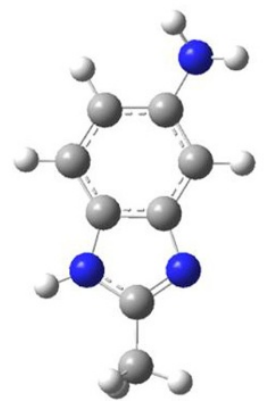

6-NH2-2- $\mathrm{CH}_{3}-\mathrm{BI}$

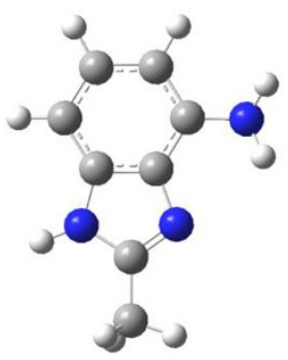

7-NH2-2- $\mathrm{CH}_{3}-\mathrm{BI}$

Figure 2 B3LYP/6-31G++(d,p) optimized geometries, $\mathrm{HOMO}$ and LUMO of 2-methylbenzimidazole $\left(2-\mathrm{CH}_{3}-\mathrm{BI}\right)$ and the optimized geometries of eight models. 
Table 3 Quantum-chemical parameters for 2-methylbenzimidazole (2- $\mathrm{CH}_{3}-\mathrm{BI}$ ) and eight models obtained using DFT at the B3LYP/6-31G++ (d,p) level

\begin{tabular}{llllccc}
\hline Molecules & Total Energy a.u. & EHOMO eV & ELUMO eV & Gap energy (ELUMO - EHOMO ) eV & $\begin{array}{c}\text { Ionization } \\
\text { potential (I) }\end{array}$ & $\begin{array}{c}\text { Electron } \\
\text { affinity (A) }\end{array}$ \\
\hline 2-CH3-BI & -419.3013 & -6.2611 & -0.6963 & 5.5648 & 6.2611 & 0.6963 \\
4-NO2-2-CH3-BI & -623.8708 & -7.0401 & -2.9818 & 4.0583 & 7.0401 & 2.9818 \\
4-NH2-2-CH3-BI & -474.6748 & -5.6826 & -0.6966 & 4.9860 & 5.6826 \\
5-NO2-2-CH3-BI & -623.8672 & -7.1062 & -2.7092 & 4.3970 & 7.1062 \\
5-NH2-2-CH3-BI & -474.6754 & -5.3555 & -0.5034 & 4.8521 & 5.6966 \\
6-NO2-2-CH3-BI & -623.8669 & -7.0418 & -2.5557 & 4.4861 & 7.7555 \\
6-NH2-2-CH3-BI & -474.6746 & -5.3721 & -0.5992 & 4.7729 & 0.50318 \\
7-NO2-2-CH3-BI & -623.8576 & -6.9794 & -2.4945 & 4.4849 & 5.3721 \\
7-NH2-2-CH3-BI & -474.6807 & -5.3220 & -0.4743 & 4.8477 & 6.5557 \\
\hline
\end{tabular}

without symmetry restrictions using the valence and polarization basis set $(6-31 \mathrm{G}++(\mathrm{d}, \mathrm{p}))[44,45]$. A combination of the Becke three-parameter hybrid (B3) $[46,47]$ exchange functional and the Lee-Yang-Parr (LYP) [48] correlation functional (B3LYP) [49,50], a version of the (DFT) method [51,52] was used to determine all optimized geometries, HOMO energies (EHOMO), LUMO energies (ELUMO), and physical properties for the molecules in this study.

\section{Results and discussion}

Two different groups were chosen as substituents of the corrosion inhibitor molecules BI, 2-CH3-BI, and 2-SH$\mathrm{BI}$ to include the most important electronic effects. The first group (nitro (-NO2)) is a strong acceptor, while the second (amino (-NH2)) is a strong donor. The nitration of corrosion inhibitor molecules yielded four models for each of the corrosion inhibitor molecules, and the same number of models was obtained for the reduced nitro group [53].

\section{Benzimidazole (BI)}

The four positions of the nitro group substituent on the benzene ring in $\mathrm{BI}$ were $\mathrm{C}-4, \mathrm{C}-5, \mathrm{C}-6$ and $\mathrm{C}-7$. These positions make the same contribution to both the HUMO and LUMO levels with a small difference, as shown in Figure 1. Figure 1 also shows the structures of the optimized geometries for BI and the models studied. Table 1 presents the EHOMO, ELUMO and energy gap values for (BI) and all models. The ionization potential (I) and the electron affinity (A) were calculated by application of Koopman's theorem [54]. This theorem establishes a relationship between the energies of the HOMO and the LUMO and the ionization potential and electron affinity, respectively.

$$
\begin{aligned}
& \mathrm{I}=- \text { EHOMO } \\
& \mathrm{A}=- \text { ELUMO }
\end{aligned}
$$

Table 2 presents the calculated values of inhibition efficiency \% for BI and eight models, which were determined using the following formula:

$$
\begin{aligned}
& I_{a d d} \%=\frac{I_{B I}-I_{x-B I}}{I_{B I}} \times 100 \% \\
& I e_{a d d} \%=I_{a d d} \% \times I e_{B I} \% \\
& I e_{\text {theor. }} \%=I e_{B I} \%+I e_{a d d .} \%
\end{aligned}
$$

Where $I_{a d d} \%$ is the percentage ionization potential of the additive for model $(x-B I), I e_{a d d} \%$ is the inhibition efficiency \%of the additive, and $I e_{\text {theor. }} \%$ is the theoretically calculated percentage inhibition efficiency.

These results demonstrate that the nitration of corrosion inhibitor molecules lead to a decrease in inhibition efficiency; the most efficient inhibitor was model (4-NO2-BI), which displayed an inhibition efficiency of $64.075 \%$. By

\begin{tabular}{|c|c|c|c|c|}
\hline \multirow[t]{2}{*}{ Molecules } & \multirow[t]{2}{*}{$I_{\text {add. }} \%$} & \multirow[t]{2}{*}{$l e_{\text {add. }} \%$} & \multicolumn{2}{|c|}{ Inhibition efficiency \% } \\
\hline & & & $\begin{array}{l}\text { Theoretical } \\
\left(\mid e_{\text {theor. }} \%\right)\end{array}$ & Experimental \\
\hline $2-\mathrm{CH} 3-\mathrm{Bl}$ & 0 & 0 & 76.300 & 76.3 \\
\hline 4-NO2-2-CH3-BI & -12.442 & -9.493 & 66.807 & - \\
\hline 4-NH2-2-CH3-BI & +9.240 & +7.050 & 83.350 & . \\
\hline 5-NO2-2-CH3-Bl & -13.498 & -10.299 & 66.001 & \\
\hline $5-\mathrm{NH}_{2}-2-\mathrm{CH} 3-\mathrm{BI}$ & +14.464 & +11.036 & 87.336 & . \\
\hline 6-NO2-2-CH3-BI & -12.469 & -9.514 & 66.786 & - - \\
\hline 6-NH2-2-CH3-BI & +14.199 & +10.834 & 87.134 & -— \\
\hline 7-NO2-2-CH3-BI & -11.472 & -8.753 & 67.547 & -— \\
\hline $7-\mathrm{NH}_{2}-2-\mathrm{CH} 3-\mathrm{BI}$ & +14.999 & +11.444 & 87.744 & - - \\
\hline
\end{tabular}
contrast, reduction of the nitro group led to an increase in inhibition efficiency; the most efficient inhibitor was model

Table 4 Calculated inhibition efficiency \% for 2-methylbenzimidazole (2- $\left.\mathrm{CH}_{3}-\mathrm{BI}\right)$ and eight models 
(7-NH2-BI), which displayed an inhibition efficiency of $85.609 \%$. The inhibition efficiency of BI was $73.8 \%$. These results represent a significant improvement in the inhibition efficiency of BI.

\section{Methylbenzimidazole (2-CH3-BI)}

The nitro group can be substituted at positions $\mathrm{C}-4$, $\mathrm{C}-5, \mathrm{C}-6$ and $\mathrm{C}-7$ on the benzene ring in 2- CH3-BI. These positions make the same contributions to the HUMO and LUMO levels, with the exception of position C-7, which is poor in the HUMO level as shown in Figure 2. Figure 2 also presents the structures of the optimized geometries for 2-CH3-BI and the studied models. Table 3 presents the EHOMO, ELUMO and energy gap values for (2-CH3-BI) and all models. Koopmans' theorem was used to calculate I and A [50].

Table 4 presents the calculated values of inhibition efficiency $\%$ for $2-\mathrm{CH} 3-\mathrm{BI}$ and eight models, which were determined using the following formula:

$$
\begin{aligned}
& I_{\text {add. }} \%=\frac{I_{2-\mathrm{CH}_{3}-\mathrm{BI}}-I_{x-2-\mathrm{CH}_{3}-\mathrm{BI}}}{I_{2-\mathrm{CH}_{3}-\mathrm{BI}}} \times 100 \% \\
& I e_{\text {add }} . \%=I_{\text {add. }} \% \times I e_{2-C \mathrm{H}_{3}-B I} \% \\
& I e_{\text {theor. }} \%=I e_{2-C H_{3}-B I} \%+I e_{\text {add }} \%
\end{aligned}
$$

Where $I_{a d d} \%$ is the percentage of ionization potential additive for model $\left(x-2-\mathrm{CH}_{3}-\mathrm{BI}\right), \mathrm{I} e_{\text {add. }} \%$ is the

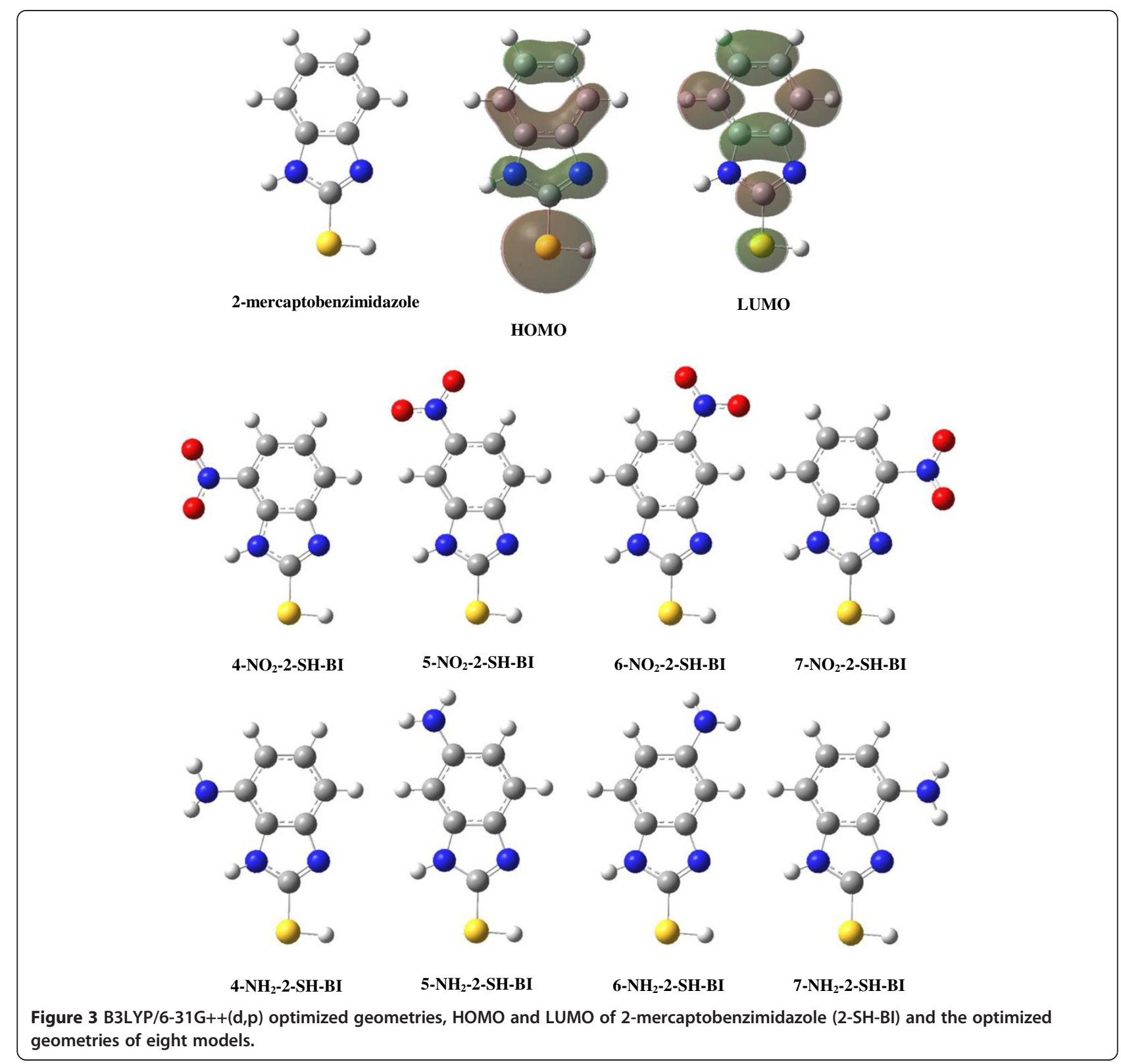


Table 5 Quantum-chemical parameters for 2-mercaptobenzimidazole (2-SH-BI) and eight models determined using DFT at the B3LYP/6-31G++ (d,p) level

\begin{tabular}{lllllll}
\hline Molecules & Total Energy a.u. & EHOMO eV & ELUMO eV & Gap energy eV & lonization potential (I) & Electron affinity (A) \\
\hline 2-SH-BI & -778.1839 & -6.1585 & -0.8242 & 5.3343 & 6.1585 & 0.8242 \\
4-NO2-2-SH-BI & -982.7523 & -6.7906 & -3.0743 & 3.7163 & 6.7906 & 3.0743 \\
4-NH2-2-SH-BI & -833.5576 & -5.8358 & -0.7747 & 5.0611 & 5.8358 & 0.7747 \\
5-NO2-2-SH-BI & -982.7492 & -6.9024 & -2.7856 & 4.1168 & 6.9024 & 2.7856 \\
5-NH2-2-SH-BI & -833.5580 & -5.3873 & -0.6332 & 4.7541 & 5.3873 & 0.6332 \\
6-NO2-2-SH-BI & -982.7486 & -6.8461 & -2.6580 & 4.1881 & 6.8461 & 2.6580 \\
6-NH2-2-SH-BI & -833.5575 & -5.4698 & -0.7189 & 4.7509 & 5.4698 & 0.7189 \\
7-NO2-2-SH-BI & -982.7398 & -6.7707 & -2.6172 & 4.1535 & 6.7707 & 2.6172 \\
7-NH2-2-SH-BI & -833.5630 & -5.4480 & -0.6713 & 4.7767 & 5.4480 & 0.6713 \\
\hline
\end{tabular}

percentage of inhibition efficiency additive, and $I e_{\text {theor }}$. $\%$ is the theoretical calculated percentage of inhibition efficiency.

These results demonstrate that the nitration of corrosion inhibitor molecules decreases the inhibition efficiency; the highest inhibition efficiency, 66.001\%, was obtained for the model (5-NO2-2-CH3-BI). By contrast, reduction of the nitro group led to an increase in inhibition efficiency; the highest inhibition efficiency, $87.44 \%$, was observed for the model (7-NH2-2-CH3-BI). The inhibition efficiency of 2-CH3-BI was $76.3 \%$. These results represent a significant improvement in the inhibition efficiency of 2-CH3-BI.

\section{Mercaptobenzimidazole (2-SH-BI)}

The positions on the benzene ring in 2-SH-BI that were substituted with nitro groups were C-4, C-5, C-6 and $\mathrm{C}-7$. These positions make the same contribution to both the HUMO and LUMO levels, with a small difference as shown in Figure 3. Figure 3 also shows the structures of the optimized geometries for 2-SH-BI and the studied models. Table 5 presents the EHOMO, ELUMO and energy gap values for 2-SH-BI and all models. Koopman's theorem was used to calculate I and $\mathrm{A}[50]$.

Table 6 presents the calculated values of inhibition efficiency \% for 2-SH-BI and eight models, which were determined using the following formula:

$$
\begin{aligned}
& I_{a d d .} \%=\frac{I_{2-S H-B I}-I_{x-2-S H-B I}}{I_{2-S H-B I}} \times 100 \% \\
& I e_{a d d .} \%=I_{a d d .} \% \times I e_{2-S H-B I} \% \\
& I e_{\text {theor. }} \%=I e_{2-S H-B I} \%+I e_{a d d} . \%
\end{aligned}
$$

Where $I_{a d d} \%$ is the percentage of ionization potential additive for model $(x-2-S H-B I), I e_{a d d} \%$ is the percentage of inhibition efficiency additive, and $I e_{\text {theor. }} \%$ is the theoretically calculated percentage of inhibition efficiency.

These results demonstrate that the nitration of corrosion inhibitor molecules led to a decrease in inhibition efficiency; the highest inhibition efficiency, $79.217 \%$, was obtained for the model (5-NO2-2-SH-BI). By contrast, reduction of the nitro group led to an increase in inhibition efficiency; the highest inhibition efficiency, 101.382\%, was obtained for the model (5-NH2-2-SH-BI). The inhibition efficiency of 2-SH-BI was $90.1 \%$. These results represent a significant improvement in the inhibition efficiency of 2-SH-BI.

\section{Conclusions}

DFT quantum-chemical calculations established a correlation between parameters related to electronic structure and the corrosion inhibition potential of the three corrosion inhibitor molecules $\mathrm{BI}, 2-\mathrm{CH} 3-\mathrm{BI}$, and 2-SH$\mathrm{BI}$, as well as eight models for each inhibitor molecule. Most of the molecular parameters calculated at the B3LYP/6-311G++(d,p) level indicated that the nitration of corrosion inhibitor molecules led to a decrease in

\begin{tabular}{|c|c|c|c|c|}
\hline \multirow[t]{2}{*}{ Molecules } & \multirow[t]{2}{*}{$I_{\text {add. }} \%$} & \multirow[t]{2}{*}{$l e_{\text {add. }} \%$} & \multicolumn{2}{|c|}{ Inhibition efficiency \% } \\
\hline & & & $\begin{array}{l}\text { Theoretical } \\
\text { (le } \text { theor. } \%)^{\text {the }}\end{array}$ & Experimental \\
\hline 2-SH-BI & 0 & 0 & 90.1 & 90.1 \\
\hline 4-NO2-2-SH-BI & -10.264 & -9.248 & 80.852 & 一 \\
\hline 4-NH2-2-SH-BI & +5.240 & +4.721 & 94.821 & 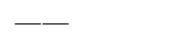 \\
\hline 5-NO2-2-SH-BI & -12.079 & -10.883 & 79.217 & - - \\
\hline 5-NH2-2-SH-Bl & +12.522 & +11.282 & 101.382 & - \\
\hline 6-NO2-2-SH-BI & -11.165 & -10.060 & 80.040 & - - \\
\hline $6-\mathrm{NH} 2-2-\mathrm{SH}-\mathrm{BI}$ & +11.183 & +10.076 & 100.176 & - - \\
\hline 7-NO2-2-SH-BI & -9.9407 & -8.950 & 81.150 & - - \\
\hline 7-NH2-2-SH-BI & +11.537 & +10.394 & 100.494 & - - \\
\hline
\end{tabular}

Table 6 Calculated inhibition efficiency \% for 2-mercaptobenzimidazole (2-SH-BI) and eight models 
inhibition efficiency, while reduction of the nitro group led to an increase in inhibition efficiency. These results represent a significant improvement in inhibition efficiency compared to previously reported corrosion inhibitor molecules. An excellent correlation between inhibition efficiency and the studied models was obtained, confirming the reliability of the method employed.

\section{Competing interests}

The authors declare that there is no conflict of interests regarding the publication of this paper

\section{Authors' contribution}

HO carried out DFT studies. GA carried out the screening studies on corrosion. AA carried out the calculation of inhibition efficiency. AA carried out the computational experiments. AK conceived of the study. AM draft the manuscript. All authors read and approved the final manuscript.

\section{Author details}

'Applied Chemistry Division, Applied Science Department, University of Technology, Baghdad, Iraq. ${ }^{2}$ Ministry of Sciences and Technology, Industrial Research \& Development Directorate, Industrial Applications Center, Baghdad, Iraq. ${ }^{3}$ Environmental Research Center, University of Technology (UOT), Baghdad 10001, Iraq. ${ }^{4}$ Department of Chemical \& Process Engineering, Universiti Kebangsaan Malaysia (UKM), Bangi, Selangor 43000, Malaysia.

Received: 18 January 2014 Accepted: 21 March 2014

Published: 27 March 2014

\section{References}

1. Uhlig HH, Revie RW: Corrosion and Corrosion Control. 3rd edition. New York John Wiley \& Sons; 1985:1.

2. Sastri VS: Corrosion Inhibitors: principles and applications. New York: John Wiley \& Sons Ltd; 1998:25-237.

3. Duda Y, Govea-Rueda R, Galicia M, Beltran HI, Zamudio-Rivera LS: Corrosion inhibitors: design, performance, and computer simulations. J Phys Chem 2005, B109:22674-22684

4. Gmez B, Likhanova NV, Dominguez Aguilar MA, Olivares O, Hallen JM, Martinez-MagadUn JM: Theoretical study of a new group of corrosion inhibitors. J Phys Chem A 2005, 109:8950-8957.

5. Rodrsguez-Valdez LM, Martunez-Villafãne A, Glossman-Mitnik D: Computational simulation of the molecular structure and properties of heterocyclic organic compounds with possible corrosion inhibition properties. J. Mol. Struct.-Theochem 2005, 713:65-70.

6. Abd El-Maksoud SA: Electrochim Acta 2004, 49:4205

7. Quartarone G, Bellomi T, Zingales A: Corros Sci 2003, 45:715.

8. Zucchi F, Trabanelli G, Fonsati M: Corros Sci 1996, 38:2019.

9. Wang DX, Li SY, Ying Y, Wang MJ, Xiao HM, Chen ZX: Corros Sci 1999, 41:1911.

10. Ravichandran R, Rajendran N: Appl Surf Sci 2005, 241:449.

11. Jamil HE, Shriri A, Boulif R, Bastos C, Montemor MF, Ferreira MGS: Electrochim Acta 2004, 49:2753.

12. Noor EA: The inhibition of mild steel corrosion in phosphoric acid solutions by some $\mathrm{N}$-heterocyclic compounds in the salt form. Corros Sci 2005, 47:33-55.

13. Avci G: Inhibitor effect of N, NO-methylenediacrylamide on corrosion behavior of mild steel in $0.5 \mathrm{M} \mathrm{HCl}$. Mater Chem Phys 2008, 112:234-238.

14. Shukla SK, Quraishi MA: Cefotaxime sodium: a new and efficient corrosion inhibitor for mild steel in hydrochloric acid solution. Corros Sci 2009, 51:1007-1011

15. de Souza FS, Spinelli A: Caffeic acid as a green corrosion inhibitor for mild steel. Corros Sci 2009, 51:642-649.

16. Bentiss F, Traisnel M, Gengembre L, Lagrenee M: A new triazole derivative as inhibitor of the acid corrosion of mild steel: electrochemical studies, weight loss determination, SEM and XPS. Appl Surf Sci 1999, 152:237-249.

17. Wang L: Evaluation of 2-mercaptobenzimidazole as corrosion inhibitor for mild steel in phosphoric acid. Corros Sci 2001, 43:2281-2289.
18. Popova M, Christov T: Deligeorgiev, Influence of the molecular structure on the inhibitor properties of benzimidazole derivatives on mild steel corrosion in $1 \mathrm{M}$ hydrochloric acid. Corrosion 2003, 59:756-764.

19. Khaled KF: The inhibition of benzimidazole derivatives on corrosion of iron in $1 \mathrm{M} \mathrm{HCl}$ solutions. Electrochim Acta 2003, 48:2493-2503.

20. Zhang F, Tang Y, Cao Z, Jing W, Wu Z, Chen Y: Performance and theoretical study on corrosion inhibition of 2-(4-pyridyl)-benzimidazole for mild steel in hydrochloric acid. Corros Sci 2012, 61:1-9.

21. Obot IB, Obi-Egbedi NO: Theoretical study of benzimidazole and its derivatives and their potential activity as corrosion inhibitors. Corros Sci 2010, 52:657-660.

22. Ahamad MA: Quraishi, Bis (benzimidazol-2-yl) disulphide: an efficient water soluble inhibitor for corrosion of mild steel in acid media. Corros Sci 2009, 51:2006-2013.

23. Ahamad MA: Quraishi, Mebendazole: new and efficient corrosion inhibitor for mild steel in acid medium. Corros Sci 2010, 52:651-656.

24. Popova M, Christov A: Vasilev, Inhibitive properties of quaternary ammonium bromides of $\mathrm{N}$-containing heterocycles on acid mild steel corrosion. Part II: EIS results. Corros Sci 2007, 49:3290-3302.

25. Christov M, Popova A: Adsorption characteristics of corrosion inhibitors from corrosion rate measurements. Corros Sci 2004, 46:1613-1620.

26. Popova M, Christov S, Raicheva E: Sokolova, Adsorption and inhibitive properties of benzimidazole derivatives in acid mild steel corrosion. Corros Sci 2004, 46:1333-1350.

27. Growcock FB, Lopp VR: The inhibition of steel corrosion in hydrochloric acid with 3-phenyl-2-propyn-1-ol. Corrosion Science 1988, 28(4):397-410

28. Khalil N: Electrochimica Acta 2003, 48:2635.

29. Lukovits I, Pa'lfi K, Bako' I, Ka'Ima'n E: LKP model of the inhibition mechanism of thiourea compounds. Corrosion, 53:915-917.

30. Bentiss F, Traisnel M, Vezin H, Lagrene'e M: Linear resistance model of the inhibition mechanism of steel in $\mathrm{HCl}$ by triazole and oxadiazole derivatives: structure-activity correlations. Corrosion Science 2003, 45(2):371-380.

31. Abdul-Ahad PG, Al-Madfai SHF: Elucidation of corrosion inhibition mechanism by means of calculated electronic indexes. Corrosion 1989, 45:978-980.

32. Cruz J, Pandiyan T, Garc'ia-Ochoa E: J. Electroanal. Chem. 2005, 583:8.

33. Cruz J, Mart'inez R, Genesca J, Garc'la-Ochoa E: Experimental and theoretical study of 1-(2-ethylamino)-2-methylimidazoline as an inhibitor of carbon steel corrosion in acid media. J. Electroanal. Chem 2004, 566:111-121.

34. Sayo's R, Gonza'lez M, Costa JM: On the use of quantum chemical methods as an additional tool in studying corrosion inhibitor substances. Corrosion Science 1986, 26(11):927-934.

35. O" G, Mihci B, Bereket G: J Mol Struct Theochem 1999, 488:223.

36. Li SL, Wang YG, Chen SH, Yu R, Lei SB, Ma HY, Liu DX: Some aspects of quantum chemical calculations for the study of Schi€ base corrosion inhibitors on copper in $\mathrm{NaCl}$ solutions. Corrosion Science 1999, 41:1769-1782.

37. Lukovits I, Ka'Ima'n E, Zucchi F: Corrosion inhibitors-correlation between electronic structure and efficiency. Corrosion 2001, 57:3-8

38. Martinez $\mathrm{S}$ : Inhibitory mechanism of mimosa tannin using molecular modeling and substitutional adsorption isotherms. Materials Chemistry and Physics 2003, 77(1, 2):97-102.

39. Bereket G, Gretir CO", Zpahin CO": Journal of Molecular Structure (Theochem) 2003, 663:39.

40. Cruz J, Garcl'a-Ochoa E, Castro M: Experimental and Theoretical Study of the 3-Amino-1,2,4-triazole and 2-Aminothiazole Corrosion Inhibitors in Carbon Steel. J. Electrochem. Soc 2003, 150:B26.

41. Awad MK: J Electroanal Chem 2004, 567:219

42. Blajiev O, Hubin A: Electrochimica Acta 2004, 49:2761.

43. Frisch MJ, Trucks GW, Schlegel HB, Scuseria GE, Robb MA, Cheeseman JR, Scalmani G, Barone V, Mennucci B, Petersson GA, Nakatsuji H, Caricato M, Li X Hratchian HP, Izmaylov AF, Bloino J, Zheng G, Sonnenberg JL, Hada M, Ehara M, Toyota K, Fukuda R, Hasegawa J, Ishida M, Nakajima T, Honda Y, Kitao O, Nakai H, Vreven T, Montgomery JA: Gaussian 09 series programs-Revision A. Wallingford, CT, USA: Gaussian, Inc; 2009:1.

44. Pietro WJ, Frand MM, Hehre WJ, Defrees DJ, Pople JA, Binkley JS: Self-consistent molecular orbital methods. 24. Supplemented small split-valence basis sets for second-row elements. J. Am. Chem. Soc 1982, 104(19):5039-5048.

45. Dobbs KD, Hehre WJ: Molecular orbital theory of the properties of inorganic and organometallic compounds 5. Extended basis sets for first-row transition metals. J Comput Chem 1987:861-879. 
46. Becke AD: Density-functional exchange-energy approximation with correct asymptotic behavior. Phys. Rev 1988, 38:3098-3100.

47. Becke AD: Density-functional thermochemistry-III. The role of exact exchange. J Chem. Phys 1993, 98(7):5648-5652.

48. Lee C, Yang W, Parr RG: Development of the ColleSalvetti correlation-energy formula into a functional of the electron density. Phys. Rev 1988, 37:785-789.

49. Al-Amiery AA, Jaffar HD, Obayes HR, Musa AY, Kadhum AH, Mohamad A: Thermodynamic studies on 4-aminocoumarin tautomers. Int J Electrochem. Sci 2012, 7:8468-8472.

50. Naama JH, Alwan GH, Obayes HR, Al-Amiery A, Al-Temimi A, Kadhum AH, Mohamad A: Curcuminoids as antioxidants and theoretical study of stability of curcumin isomers in gaseous state. Res Chem Intermediat 2013, 39(9):4047-4059.

51. Obayes HR, Al-Amiery AA, Jaffar HD, Musa AY, Kadhum AH, Mohamad A: "Theoretical study for the preparation of sub-carbon nano tubes from the cyclic polymerization reaction of two molecules from corannulene, coronene and circulene aromatic compounds". J. Comput. Theor. Nanosci 2013, 10:2459-2463.

52. Obayes HR, Alwan GH, Al-Amiery AA, Kadhum AH, Mohamad A: Thermodynamic and theoretical study of the preparation of new buckyballs from corannulene, coronene, and circulene. J Nanomater 2013, 2013:8. Article ID 451920.

53. Fomina L, Porta B, Acosta A, Fomine S: Novel substituted 1-amino-4,5, 8-naphthalenetricarboxylic acid-1,8-lactam-4,5-imides: experimental and theoretical study. J. Phys. Org. Chem. 2000, 13:705-712.

54. Lukovits I, Kalman E, Zucchi F: Corrosion inhibitors-correlation between electronic structure and efficiency. Corrosion 2001, 57:3-8.

doi:10.1186/1752-153X-8-21

Cite this article as: Obayes et al:: Quantum chemical assessment of benzimidazole derivatives as corrosion inhibitors. Chemistry Central Journal 2014 8:21.

\section{Publish with ChemistryCentral and every scientist can read your work free of charge \\ "Open access provides opportunities to our colleagues in other parts of the globe, by allowing anyone to view the content free of charge." \\ W. Jeffery Hurst, The Hershey Company. \\ - available free of charge to the entire scientific community \\ - peer reviewed and published immediately upon acceptance \\ - cited in PubMed and archived on PubMed Central \\ - yours - you keep the copyright \\ Submit your manuscript here: \\ http://www.chemistrycentral.com/manuscript/<smiles>c1ccccc1</smiles> \\ Chemistry Central}

